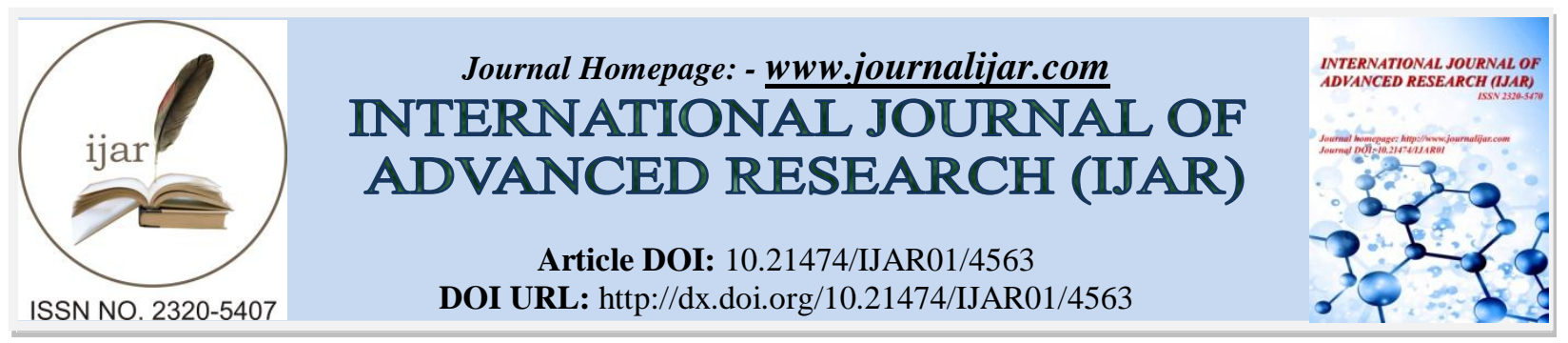

RESEARCH ARTICLE

\title{
GREEN SYNTHESIS, CHARACTERIZATION AND ELECTROCATALYTIC APPLICATION OF CURCUMIN CONJUGATED RUTHENIUM NANOPARTICLES.
}

\author{
A. Angel, R. Manikandan, Jency Feminus. J, S. Sriman Narayanan and "P. N. Deepa. \\ Department of Analytical Chemistry, School of Chemical Sciences, University of Madras, Guindy Campus, \\ Chennai-600 025, Tamilnadu, India.
}

\section{Manuscript Info} (1........................

\section{Manuscript History}

Received: 21 April 2017

Final Accepted: 23 May 2017

Published: June 2017

Key words:-

Green synthesis, Ruthenium nanoparticles, Modified electrode, Hydrogen peroxide, Electrocatalysis.

\section{Abstract}

Noble metal nanoparticles are emerging as important materials among the rapidly expanding domains with potential applications in many fields. In this work Ruthenium nanoparticles (RuNP) have been synthesized by a green synthetic pathway using citric acid as the reducing agent and curcumin as the stabilizing agent. The synthesized nanoparticles have been characterised by SEM, XRD and UV-vis spectroscopy. The nanoparticles have been used as an electrocatalyst for the determination of Hydrogen peroxide $\left(\mathrm{H}_{2} \mathrm{O}_{2}\right)$. The RuNP modified electrode response under hydrodynamic conditions has been studied using various voltammetric techniques. The electrode shows a good response towards electrocatalytic reduction of $\mathrm{H}_{2} \mathrm{O}_{2}$ with a linear range from $1.66 \mu \mathrm{M}$ to $54.70 \mu \mathrm{M}$. The utility of the sensor for real sample analysis has been evaluated by carrying out analysis of different milk samples and the results obtained were found to be satisfactory. The work demonstrates that the new RuNP modified electrode is a promising tool for detection of important analytes.

Copy Right, IJAR, 2017,. All rights reserved.

\section{Introduction:-}

Nanomaterials have become a topic of great interest and investment in the field of research and industries as these kinds of materials have potential applications in microelectronics (Cen et al. 2009), photocatalysis (Huang et al. 2014), chemisorption (Perenboom et al. 1981), aerosols and powder metallurgy (Schmid et al. 1995). Noble metal NP's have gained intensive commercial applications due to their exceptional optical, electronic, magnetic and catalytic properties (Mody et al. 2010; Conroy et al. 2008; Ito et al. 2005; Heilmann et al. 1999; Lopes et al. 2001; Sardar et al. 2009; Kumar et al. 2015; Mathpal et al. 2015; Heilmann et al. 2003). However, there is a serious concern regarding the hazards these engineered nanoparticles impose on the environment as a consequence of the increasing industrial and research activities (Dwivedi et al. 2015; Thomas et al. 2011; Brar et al. 2010; Bystrzejewska-Piotrowska et al. 2009; Ju-Nam et al. 2008). Hence, environmentally benign methodology for the synthesis and utilisation of these nanoparticles with aim to reduce their toxic effects is a promising field of research. In recent year's ruthenium nanoparticles have been widely used in electrochemical applications, however most of the work is for energy storage devices. (H.K Hassan et. al 2017)

Hydrogen Peroxide $\left(\mathrm{H}_{2} \mathrm{O}_{2}\right)$ is widely used in pharmaceuticals, clinic, environmental, mining, textile, paper, food manufacturing and chemical industries with its major application as a bleaching agent in textile and paper industries (Campos-Martin et al. 2006; Hage et al. 2006). It is also a co-product of various oxidases and the enzyme activity 
can be measured by detecting the amount of $\mathrm{H}_{2} \mathrm{O}_{2}$ produced. It also acts as eukaryotic signal transducer (Youdim et al. 1987). Thus, the monitoring of $\mathrm{H}_{2} \mathrm{O}_{2}$ concentration is of great industrial and biological importance (Romantsova et al. 2015). There are various methods for $\mathrm{H}_{2} \mathrm{O}_{2}$ detection (Veal et al. 2007) among which electrochemical sensing methods are most preferred as it is highly selective and the response is very fast and reliable(Garcia et al. 2014; Kurowska et al. 2013; Huang et al. 2014). Herein, we have incorporated green synthesized RuNP for electrode modification to devise a sensor for the determination of $\mathrm{H}_{2} \mathrm{O}_{2}$.

\section{Experimental:-}

\section{Apparatus:-}

All electrochemical experiments were carried out with a CHI 660B electrochemical analyzer with a standard three electrode system controlled by a personnel computer. An electrochemical cell containing $0.1 \mathrm{M}$ phosphate buffer with a RuNP modified electrode as the working electrode, a platinum wire as the counter electrode and standard calomel electrode as the reference electrode was used for the experiments. All potentials were referred to the latter. The modified electrode was prepared according to the procedure described below.

UV-Visible absorption spectra (UV-vis) were recorded using a Perkin Elmer Lambda spectrophotometer operating in the range 200-800nm. X-ray diffraction (XRD) analysis was recorded by the X-ray generator (model 3000) from Rich Seifert, Germany. Scanning electron microscopy(SEM) studies were carried out using Hitachi-S3400N Scanning Electron Microscope equipped with Electron Dispersive Spectroscopy.

\section{Reagents:-}

Ruthenium trichloride was purchased from SRL Pvt. Ltd., India. Hydrogen peroxide was obtained from Merck, India. Curcumin was extracted from fresh rhizomes using the method reported in literature (A.M Anderson et. al 2000). Graphite rods (3mm dia) has been purchased from sigma and Paraffin wax impregnated graphite electrodes were used for the modification. All other reagents were of analytical grade and used without further purification. All the solutions were prepared using double distilled water. The electrolyte solutions were purged with pure nitrogen to remove free oxygen before the experiment. The $\mathrm{pH}$ of the electrolyte solutions used was maintained at 7 using phosphate buffer.

\section{Synthesis of Ruthenium nanoparticles(RuNP):-}

$10 \mathrm{~mL}$ of $1 \mathrm{mM}$ freshly prepared aqueous solution of ruthenium trichloride was added to $10 \mathrm{~mL}$ of stored pure lemon extract with constant stirring for the reduction of ruthenium ions. The reaction mixture was kept in the magnetic hot stirrer at $50-60^{\circ} \mathrm{C}$ until the colour changes from dark black to brown colour which denotes the complete reduction of metal ions. Freshly prepared curcumin extract was added to the above solution to stabilize the nanoparticles and stirring was continued for about an hour. There was a slow colour change from brown to yellow and finally a permanent yellowish black colour indicates complete stabilisation of RuNP. The solution was centrifuged several times to obtain the pure RuNP, The supernatant was decanted and kept in oven for drying.

\section{Electrode Fabrication:-}

Drop casting method was adopted for electrode fabrication. The paraffin impregnated graphite electrode (PIGE) was prepared by the previously reported procedure (Scholz et al. 1994; Scholz et al. 1994). The graphite rods were immersed into molten wax under vacuum until air bubbles cease to evolve from the rods. After re-establishment of the atmospheric pressure the graphite rods were removed from the solution prior to solidification of paraffin. The PIGE were then polished to a mirror like finish by rubbing over a finest quality emery paper. The polished electrode was then rinsed with methanol and washed thoroughly with double distilled water. The ethanolic solution of the synthesized RuNP was then drop cast onto the surface of the PIGE. The electrode was allowed to dry at room temperature for 24 hours. The resulting RuNP modified electrode was used for further studies. All voltammograms of the modified electrodes were recorded after the electrode had reached equilibrium with the background electrolyte.

\section{Results and Discussion:-}

Surface morphology study by using SEM:-

The synthesised curcumin conjugated RuNP has been studied using SEM. Fig-1(a) and (b) are the images obtained for the nanoparticles under various magnification. The SEM shows the particles were predominantly spherical in shape and Fig-1(c) shown the EDX spectrum of RuNP. 

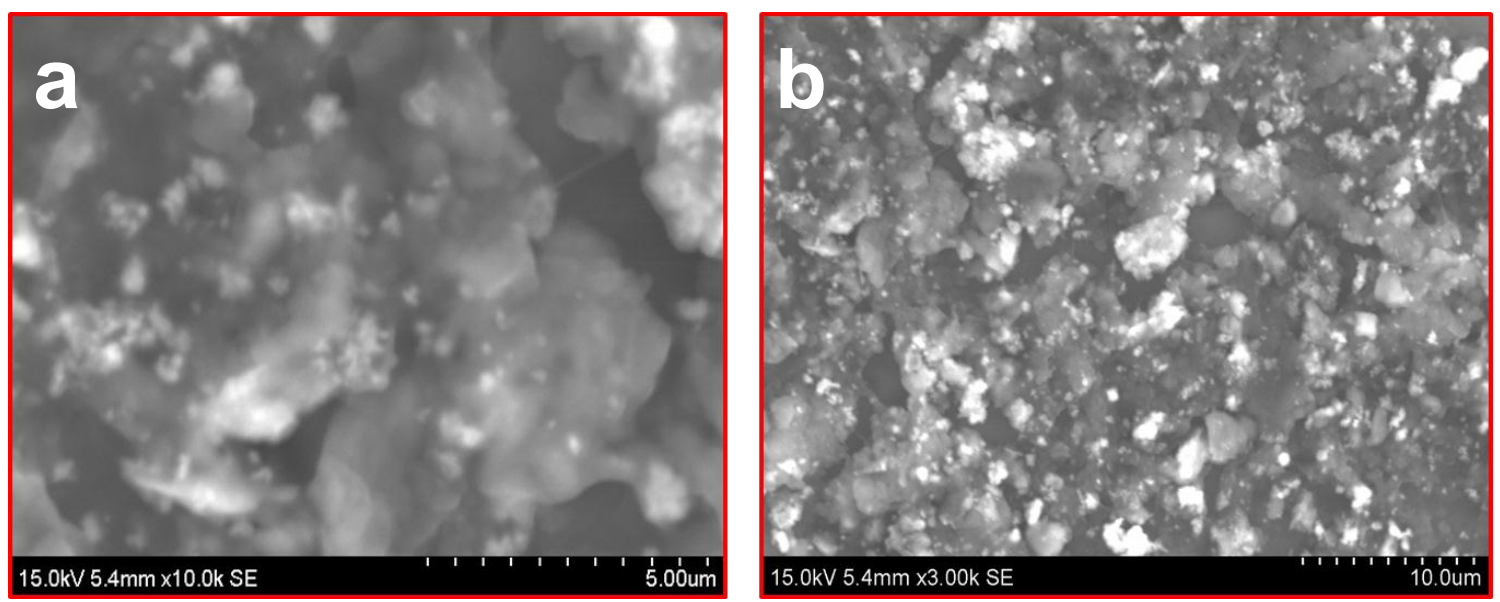

Fig.1:- (a) and (b)SEM images for the Curcumin conjugated RuNP under different magnifications.

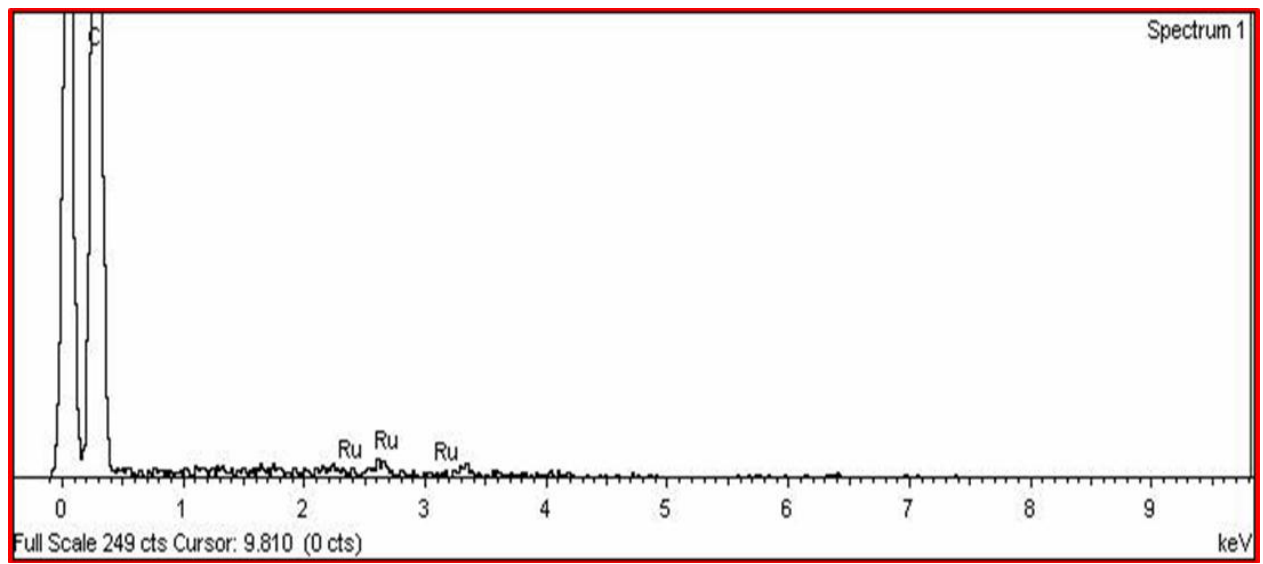

Fig.1:-(c) Curcumin conjugated RuNP EDX spectram

\section{Absorption spectral studies:-}

The formation of curcumin conjugated RuNP has been confirmed by UV-Vis and emission spectral studies. Fig-2(a) shows the yellowish pure curcumin absorption at $253 \mathrm{~nm}$ and $435 \mathrm{~nm}$ arising due to the aromatic ring structure of the molecule, Fig-2(b) is the spectrum of curcumin conjugated RuNP exhibiting absorption at $320 \mathrm{~nm} 440 \mathrm{~nm}$ corresponding to curcumin and RuNP respectively. The shift in absorptions indicates the curcumin conjugation to RuNP (Kunduet al. 2013).

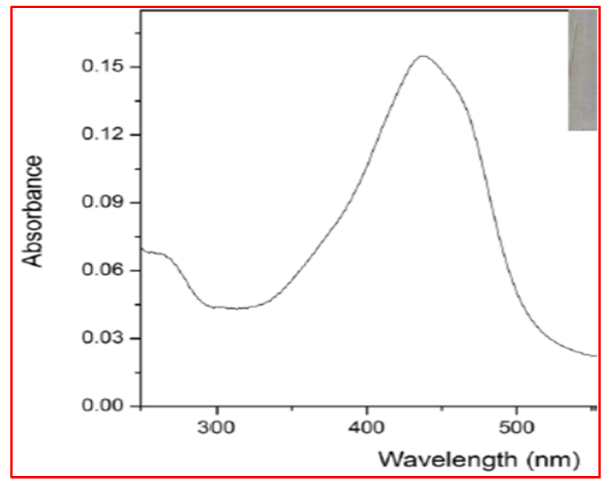

Fig.2:- (a) UV-vis absorption spectrum of synthesized curcumin in alcoholic solution. 


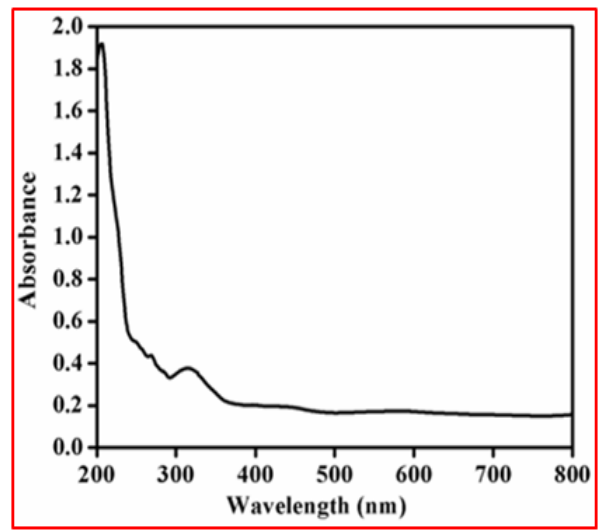

Fig.2:- (b) UV-Vis absorption spectrum of synthesized curcumin conjugated RuNP.

\section{Fourier-transform infrared (FT-IR) analysis:-}

In order to study the formation of curcumin conjugated RuNP, FT-IR technique was used and the resultsare shown in the Fig-3. A detailed study of FT-IR spectra of curcumin has been reported by Kolovet al.2005. The FT-IR spectral data for curcumin (A) shows pronounced peaks at $1381 \mathrm{~cm}^{-1}, 1463 \mathrm{~cm}^{-1}$ and $1543 \mathrm{~cm}^{-1}$ corresponding to the curcuminenol form C-O stretching. In the curcumin conjugated RuNP spectra the two peaks seem shifted to 1635 $\mathrm{cm}^{-1}$ and $1651 \mathrm{~cm}^{-1}$ corresponding to the formation of curcumin conjugated ruthenium nanoparticles. The conjugation of RuNP may be via $\mathrm{C}=\mathrm{O}$ group of curcumin.

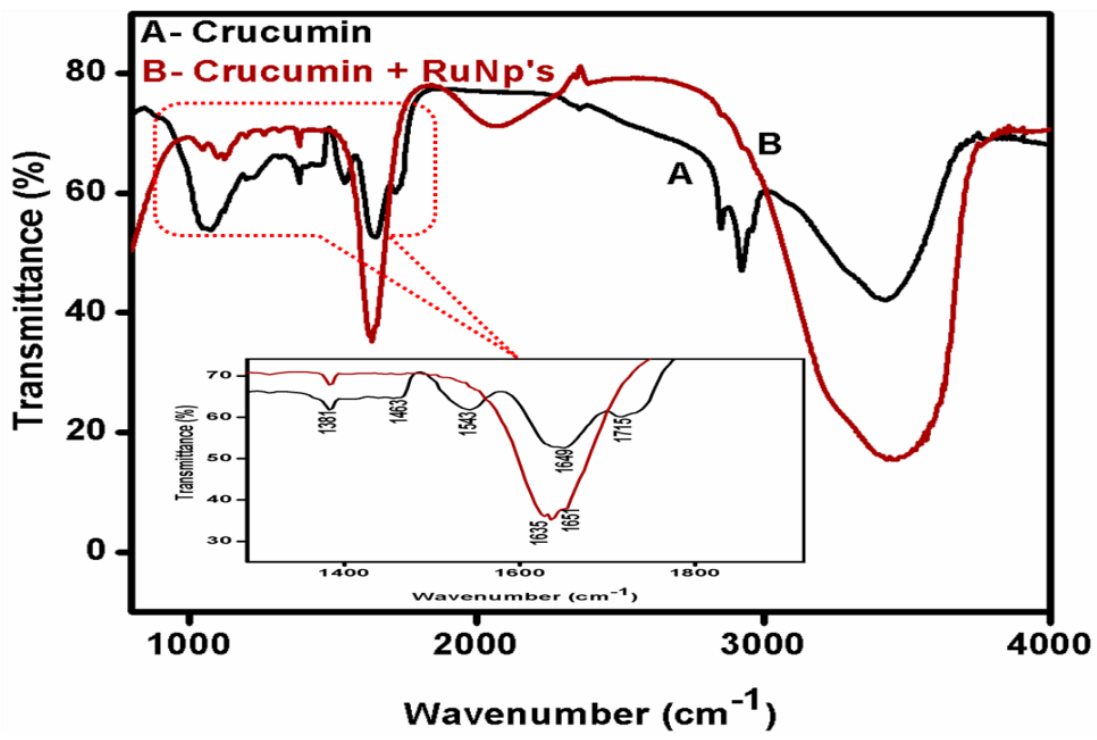

Fig.3:- FT-IR spectra of curcumin and curcumin conjugated RuNP

\section{$X$ - ray diffraction study:-}

The fig-4 shows XRD pattern of the synthesized RuNP. The three distinct diffraction peaks at 40.8, 47.4, 69.3

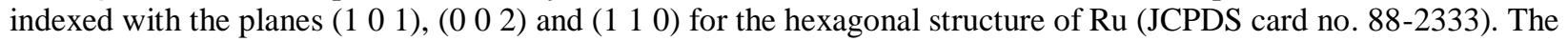
well resolved and intense XRD pattern clearly showed that the RuNP were amorphous in nature. In addition, the unassigned peaks suggest that the crystallisation of bio-organic phase occurs on the surface of the nanoparticles (Kundu et al. 2013). 


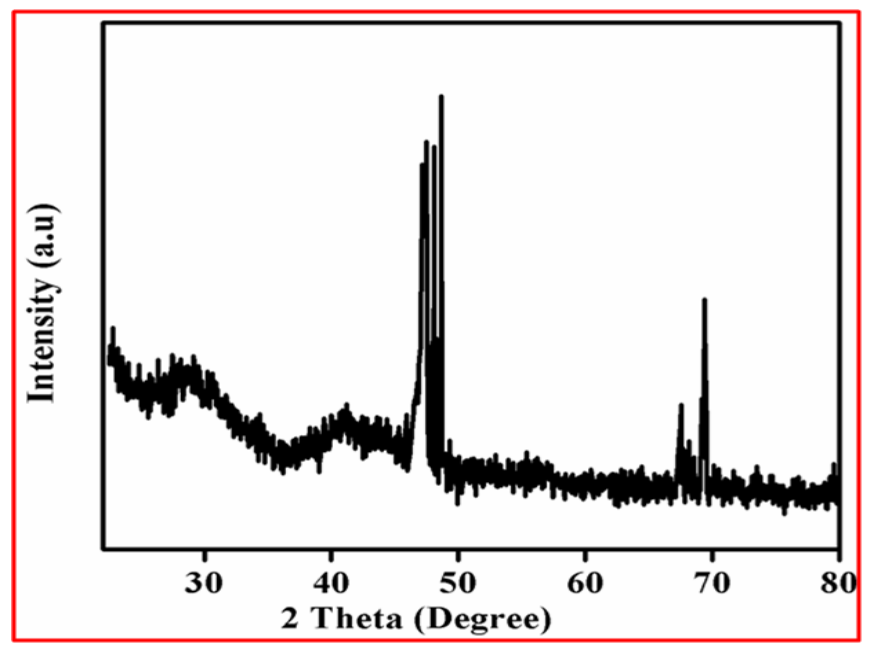

Fig.4:- XRD pattern of synthesized curcumin conjugated RuNP

\section{Electrochemical behaviour of RuNP modified Electrode:-}

\section{Cyclic voltammetric behaviour of the Curcumin conjugated RuNP:-}

The electrochemical behaviour of the curcumin conjugated RuNP has been studied by cyclic voltammetry method. The voltammogram for the RuNP modified electrode in $5 \mathrm{mM} \mathrm{K}_{4}\left[\mathrm{Fe}(\mathrm{CN})_{6}\right]^{3-4-}$ in $0.1 \mathrm{M} \mathrm{KCl}$ as background electrolyte solution is shown in Fig-5. From the voltammogram the oxidation $\left(E_{p a}\right)$ and reduction $\left(E_{p c}\right)$ peak potential for the bare PIGelectrode was found at $0.28 \mathrm{~V}$ and $0.09 \mathrm{~V}$ respectively. Whereas for the RuNP modified electrode, the voltammetric peaks were observed at $0.25 \mathrm{~V}\left(\mathrm{E}_{\mathrm{pa}}\right)$ and $0.09 \mathrm{~V}\left(\mathrm{E}_{\mathrm{pc}}\right)$. The peak to peak separation value $\left(\Delta \mathrm{E}_{\mathrm{p}}\right)$ has been $0.09 \mathrm{~V}$ and $0.08 \mathrm{~V}$ for the bare PIG electrode and curcumin conjugated RuNP modified electrode respectively. Thus, a decrease in the $\Delta \mathrm{E}_{\mathrm{p}}$ value in the case of the modified electrode suggests the curcumin conjugated RuNP modified electrodes exhibit good electrochemical properties and fast electron transfer kinetics in comparison with the bare electrode (Manikandan et al. 2017).

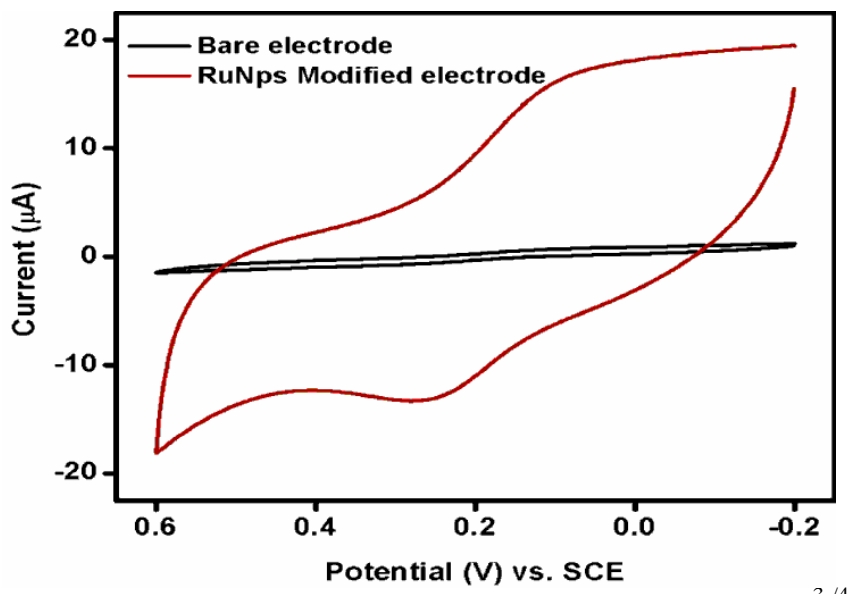

Fig. 5:- Cyclic voltammogram of bare and modified electrode in $5 \mathrm{mM} \mathrm{K}_{4}\left[\mathrm{Fe}(\mathrm{CN})_{6}\right]^{3-14}$ containing $0.1 \mathrm{M} \mathrm{KCl}$ as supporting electrolyte at scan rate of $50 \mathrm{mV} \mathrm{s}^{-1}$

Application of RuNP modified electrode towards electrocatalytic reduction of $\mathrm{H}_{2} \mathrm{O}_{2}$ by cyclic voltammetry method:-

The electrocatalytic activity of RuNP modified electrode towards $\mathrm{H}_{2} \mathrm{O}_{2}$ was studied using cyclic voltammetry. Fig-6 shows the cyclic voltammetric response of bare and modified electrode in $0.1 \mathrm{M}$ phosphate buffer ( $\mathrm{pH}-7$ ). RuNP modified electrode shows oxidation potential at $0.26 \mathrm{~V}$ and reduction at $-0.02 \mathrm{~V}$. The modified electrode in the presence of $6.6 \mu \mathrm{M}$ of $\mathrm{H}_{2} \mathrm{O}_{2}$ showed higher catalytic current with lower reduction potential when compared to bare electrode and thus exhibiting excellent electrocatalytic activity towards $\mathrm{H}_{2} \mathrm{O}_{2}$ determination. The linear response for $\mathrm{H}_{2} \mathrm{O}_{2}$ determination was in the range of $1.66 \mu \mathrm{M}$ to $25 \mu \mathrm{M}$. 


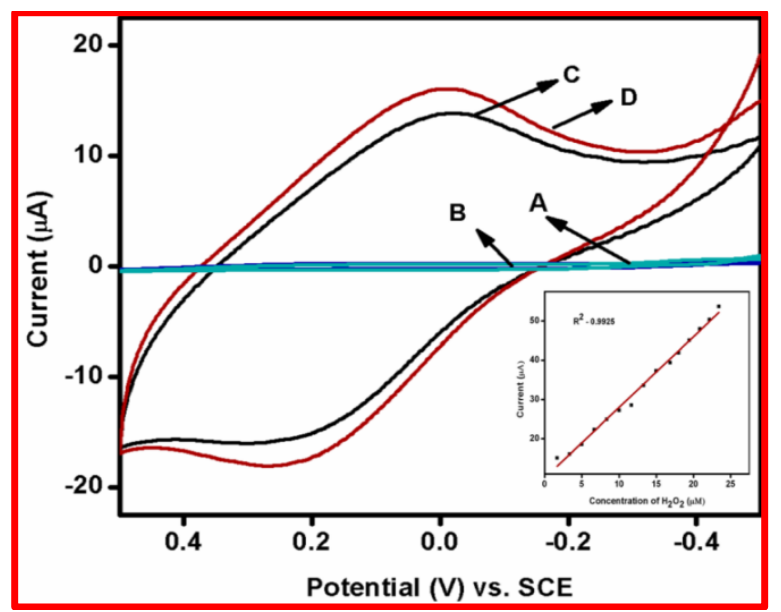

Fig.6:- Cyclic voltammetric response of bare and modified electrode in the presence of $6.6 \mu \mathrm{M}$ of $\mathrm{H}_{2} \mathrm{O}_{2}$ in $0.1 \mathrm{M}$ phosphate buffer pH-7 at scan rate of $50 \mathrm{mV} \mathrm{s}^{-1}$ inset fig. is plot of conc. of $\mathrm{H}_{2} \mathrm{O}_{2}$ vs. Current

\section{Electrocatalysis of $\mathrm{H}_{2} \mathrm{O}_{2}$ under Hydrodynamic conditions:-}

The RuNP modified electrode towards $\mathrm{H}_{2} \mathrm{O}_{2}$ was studied under hydrodynamic conditions. Fig-7 illustrates the hydrodynamic voltammogram of bare and RuNP modified electrodes in the presence of $6.6 \mu \mathrm{M} \mathrm{H}_{2} \mathrm{O}_{2}$ in phosphate buffer (pH-7) as supporting electrolyte at a potential range of -0.4 to $0.4 \mathrm{~V}$ under stirring conditions at a rate of 300 rpm. From the figure it is clear the electrocatalytic determination of $\mathrm{H}_{2} \mathrm{O}_{2}$ was very much higher using the RuNP modified electrode when compared to the bare electrode response. An enhanced current response using the RuNP modified electrode with $-0.1 \mathrm{~V}$ as the maximum was observed.

The chronoamperometric response of the RuNP modified electrode towards the reduction of $\mathrm{H}_{2} \mathrm{O}_{2}$ was studied. A potential of $-0.1 \mathrm{~V}$ was fixed for the amperometric determination on the basis of the maximum current response obtained from the hydrodynamic studies. Fig-8a shows the amperogram corresponding to the successive addition of $0.03 \mathrm{~mL}$ of $0.01 \mathrm{M}$ of $\mathrm{H}_{2} \mathrm{O}_{2}$ to $0.1 \mathrm{M}$ PBS under stirring at a rate of $300 \mathrm{rpm}$. A sharp increase in the current was observed for every addition of $\mathrm{H}_{2} \mathrm{O}_{2}$. The modified electrode also showed a fast response $(0.2 \mathrm{~s})$. Fig-8b shows the calibration plot wherein the linear range observed was from $1.66 \mu \mathrm{M}$ to $54.70 \mu \mathrm{M}$ with a detection limit of $0.53 \mu \mathrm{M}$. The sensitivity has been determined to be $5.32 \mu \mathrm{A} / \mu \mathrm{M}$ with correlation coefficient of 0.985 . The rapid response of the RuNP modified electrode for the reduction of $\mathrm{H}_{2} \mathrm{O}_{2}$ could lead to its viable application as an electrochemical sensor in flow systems.

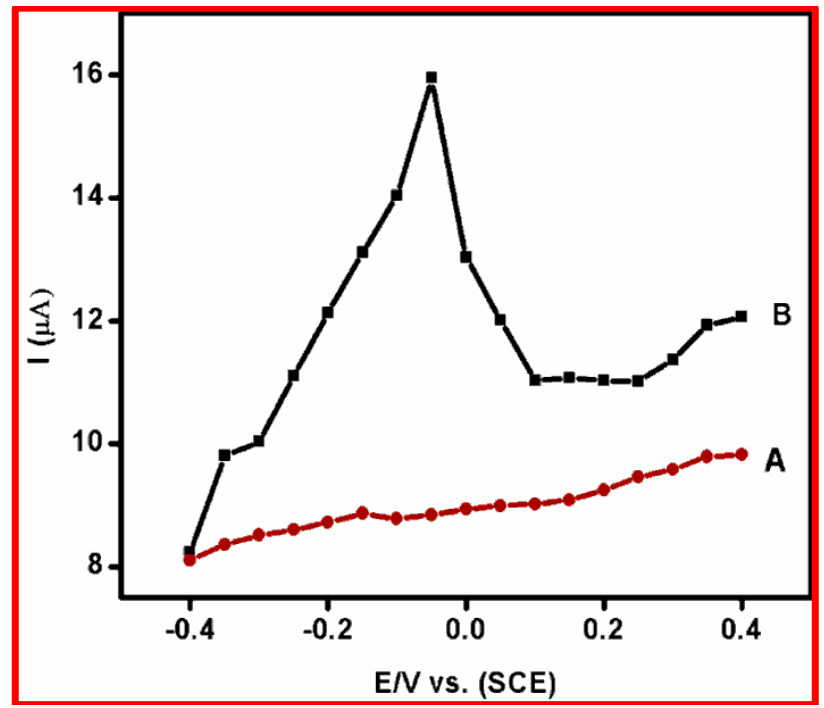

Fig.7:- The hydrodynamic voltammograms of bare (a) and modified electrode (b) in the presence of $6.6 \mu \mathrm{M}$ of $\mathrm{H}_{2} \mathrm{O}_{2}$ under the dynamic conditions in $0.1 \mathrm{M}$ phosphate buffer as supporting electrolyte 


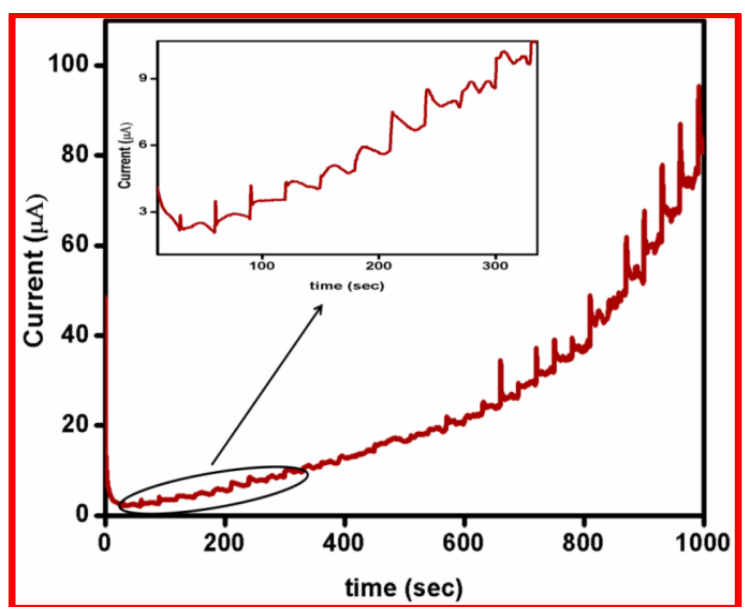

Fig.8:- (a) chronoamperometric response for the successive addition of $\mathrm{H}_{2} \mathrm{O}_{2}$ and corresponding current increase in the concentration range from 1.6 to $54.7 \mu \mathrm{M}$
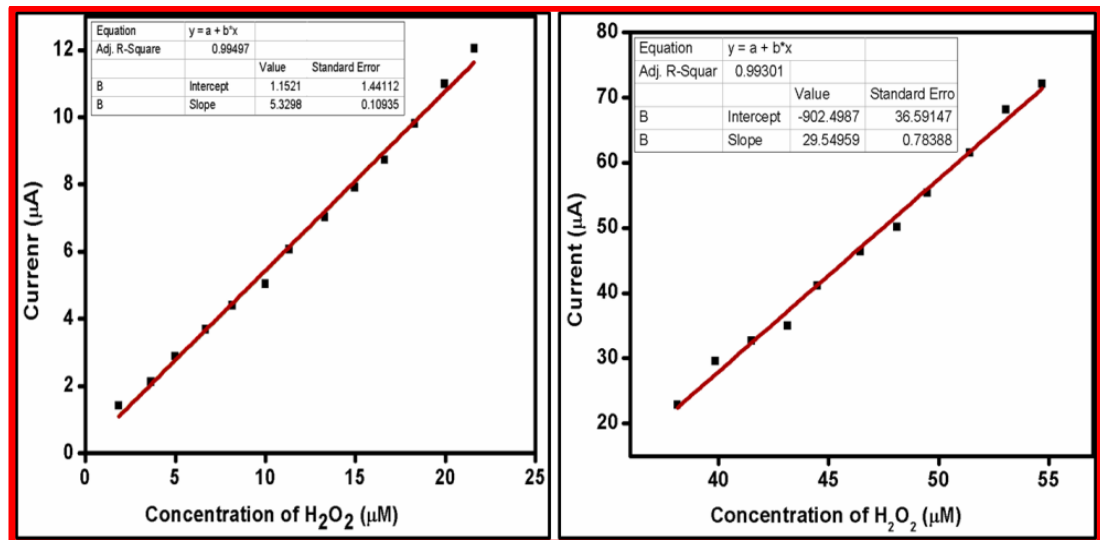

Fig.8:- (b) current vs. concentration plot for corresponding chronoamperometric response

\section{Interference studies:-}

The selective determination of $\mathrm{H}_{2} \mathrm{O}_{2}$ was investigated in the presence of different concentrations of analytes by using RuNP modified electrode. The selection of the interferents was made based on their commercial availability. Various interferents such as Ascorbic acid, Dopamine, Gallic acid, Citric acid and Uric acid were added in order to verify the selectivity of the modified electrode towards $\mathrm{H}_{2} \mathrm{O}_{2}$ (fig-9). It was found that the above compounds did not show any interference with $\mathrm{H}_{2} \mathrm{O}_{2}$ reduction as they undergo oxidation reaction at the electrode. The electrode could thus be used to selectively determine $\mathrm{H}_{2} \mathrm{O}_{2}$ in the presence of these interferents.

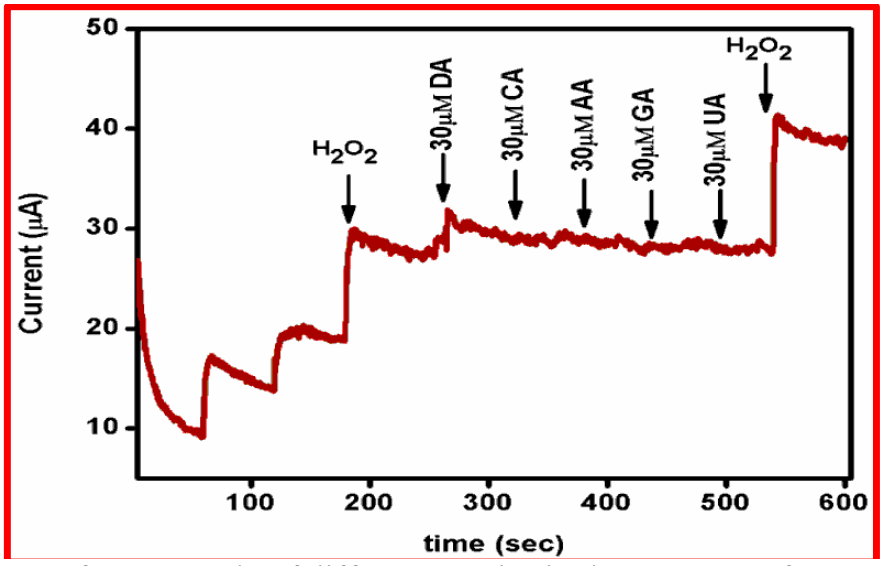

Fig.9:- Intereference study of different species in the presence of $3 \mu \mathrm{M}$ of $\mathrm{H}_{2} \mathrm{O}_{2}$. 


\section{Real sample Analysis:-}

The selective electrocatalytic property of the RuNP modified electrode makes it suitable for a wide range of analytical applications. The applicability of the modified electrode in measuring the concentration of $\mathrm{H}_{2} \mathrm{O}_{2}$ in two different brands of milk purchased commercially has been tested. The table-1 shows that analysis of $\mathrm{H}_{2} \mathrm{O}_{2}$ by standard addition methods and the recoveries obtained.

Table 1:- Determination of $\mathrm{H}_{2} \mathrm{O}_{2}$ in different milk samples.

\begin{tabular}{|c|c|c|l|}
\hline Smple ID & Added $(\mu \mathrm{M})$ & Found $(\mu \mathrm{M})$ & Recovery $(\%)$ \\
\hline I & 10 & $9.87( \pm 0.017)$ & 98.7 \\
& 20 & $19.76( \pm 0.023)$ & 98.8 \\
\hline II & 10 & $9.98( \pm 0.018)$ & 99.8 \\
& 25 & $25.2( \pm 0.024)$ & 100.8 \\
\hline
\end{tabular}

Stability of RuNP modified Electrode:-

The stability of the RuNP modified electrode was studied by cycling the electrode in phosphate buffer $\mathrm{pH}-7$ solution at a scan rate of $50 \mathrm{mVs}^{-1}$ for 100 cycles. No appreciable change in the current response and the peak potential was observed. The catalytic current for the reduction of $\mathrm{H}_{2} \mathrm{O}_{2}$ was also found to be reproducible. The RuNP modified electrode was found to exhibit high stability and reproducibility. The modified electrode was kept in air tight container in refrigerator $\left( \pm 5^{0} \mathrm{C}\right)$ when not in use.

\section{Conclusion:-}

In this study we have successfully synthesized Ruthenium nanoparticles by green synthetic pathway. The synthesized RuNP has been used for fabricating a modified electrode. The modified electrode was used for determining $\mathrm{H}_{2} \mathrm{O}_{2}$ with a linear range of $1.66 \mu \mathrm{M}$ to $54.70 \mu \mathrm{M}$ and a detection limit of $0.53 \mu \mathrm{M}$. The method successfully demonstrates the application of RuNP for electrocatalysis. The electrode has a simpler and easier fabrication process with good selectivity and sensitivity for the detection of chosen analyte with enhanced stability and reproducibility.

\section{Reference:-}

1. Anderson AM, Mitchell MS, Mohan RS (2000) Isolation of curcumin from turmeric. J Chem Educ 77:359-360

2. Brar SK, Verma M, Tyagi RD, Surampalli RY (2010) Engineered nanoparticles in wastewater and wastewater sludge - evidence and impacts, Waste Manage30:504-520

3. Bystrzejewska-Piotrowska G, Golimowski J, Urban PL (2009) Nanoparticles: their potentialtoxicity, Waste Environ Manage, Waste Manage. 29:2587-2595

4. Campos-Martin JM, Blanco-Brieva G, Fierro JLG (2006) Hydrogen peroxide synthesis: an outlook beyond the anthraquinone process. AngwChemIntEd45:6962-6984

5. Cen C, Thiel S, Mannhart J, Levy J (2009) Oxide Nanoelectronics on Demand. Science 323:1026-1030

6. Conroy S, Jerry HSL, Zhang M (2008) Magnetic nanoparticles in MR imaging and drug delivery.Adv Drug Deliv Rev60:1252-1265

7. Dwivedi AD, Dubey SP, Sillanpaa M, Kwon YN, Lee C, Varma RS (2015) Fate of engineered nanoparticles : implications in the environment. CoordChem Rev287:64-78

8. Garcia M, Batalla P, Escarpa A (2014) Metallic and polymeric nanowires for electrochemical sensing and biosensing. Trends Anal Chem57:6-22

9. Hage R, Lienke A (2006) Applications of transition-metal catalysts to textile and wood-pulp bleaching. AngwChemInt Ed45:206-222

10. Hassan HK, Atta NF, Hamed MM, Galal A, JacobT (2017) Ruthenium nanoparticles-modified reduced graphene prepared by a green method for high-performance supercapacitorapplication in neutral electrolyte. RSC Advances 7:11286-11296

11. Heilmann A (2003) Polymer Films with Embedded Metal nanoparticles. Berlin: Springer

12. Heilmann A, Keisow A, Gruner M, Kreibig U (1999) Optical and electrical properties of embedded silver nanoparticles at low temperatures. Thin Solid Films344:175-178

13. Huang W, Hua Q, Cao $T$ (2014) Influence and removal of capping ligands on catalytic colloidal nanoparticles. Catalysis letters 144:1355-1369

14. Ito A, Shinkai M, Honda H, Kobayashi T (2005) Medical application of functionalized magnetic nanoparticles. J BiosciBioeng 100:1-11 
15. Ju-Nam Y, Lead JR (2008) Manufactured nanoparticles: an overview of their chemistry, interactions and potential environmental implications. Sci Total Environ400:396- 414

16. Kumar P, Mathpal MC, Tripathi AK, Prakash J, Agarwal A, Ahmad MM, (2015) Plasmonic resonance of Ag nanoclusters diffused in soda-lime glasses. PhysChemChemPhys 17:8596-603

17. Kurowska E, Brzozka A, Jarosz M, Sulka GD, Jaskuła M (2014) Silver nanowire array sensor for sensitive and rapid detection of $\mathrm{H}_{2} \mathrm{O}_{2}$. ElectrochimActa10:4439-4447

18. Kundu S, Nithiyanantham U (2013) In situ formation of curcumin stabilized shape-selective Ag nanostructures in aqueous solution and their pronounced SERS activity. RSC Advances 3:25278-25290

19. Kolev TM, Velcheva EA, Stamboliyska BA, Spiteller M (2005) DFT and experimental studies of the structure and vibrational spectra of curcumin. International Journal of Quantum Chemistry 102:1069-1079

20. Li X, Wang L, Wu Q, Chen Z, Lin X (2014) Anonenzymatic hydrogen peroxide sensor based on Au-Ag nanotubes and chitosan film. J ElectroanalChem73:519-523

21. Lopes WA, Jaeger HM (2001) Hierarchical self-assembly of metal nanostructures on d-block copolymer scaffolds. Nature 414:735-738

22. Mathpal MC, Kumar P, Kumar S, Tripathi AK, Singh MK, Prakash J (2015)Opacity and plasmonic properties of Ag embedded glass basedmetamaterials. RSC Adv5:12555-12562

23. Mody VV, Rodney S, Singh A, ModyHardik R (2010) Introduction to metallic nanoparticles.J Pharm BioalliedSci2:282-289

24. Manikandan R, Sriman Narayanan S (2016) Differential Pulse Anodic Stripping Voltammetric Determination of Lead (II) Using Poly Xylenol Orange Modified Electrode. Electroanalysis 29:609-615

25. Perenboom JAAJ, Wyder P, Meier F (1981) Electronic properties of small metallic particles. Physics Reports 78:173-292

26. Romantsova OV, Ulybin VB (2015) Safety issues of high-concentrated hydrogenperoxide production used as rocket propellant. ActaAstron 109:231-234

27. Sardar R, Funston AM, Mulvaney P, Murray RW (2009) Gold nanoparticle, past, present and future. Langmuir25:13840-13851

28. Schmid G (1995) Chemical synthesis of large metal clusters and their properties. Nanostructured materials 6:15-24

29. Scholz F, Meyer B (1994)Electrochemical solid state analysis: state of the art. Chemical Society Reviews 23:341-347

30. Scholz F, Lange B (1992) Abrasive stripping voltammetry-an electrochemical solid state spectroscopy of wide applicability. TrAC Trends in Analytical Chemistry 11: 359-367

31. Seddon EA, Seddon KR (1984) Elsevier, Amsterdam New York pp.1373

32. Thomas CR, George S, Horst AM, Ji Z, Miller RJ, Peralta-Videa JR, Xia T, Pokhrel S, $\quad$ Mädler $\quad$ L, Gardea-Torresdey JL, Holden PA, Keller AA, Lenihan HS, Nel AE, Zink JI (2011) Nanomaterials in the environment : from materials to high through putscreening to organisms ACS Nano5:13-20

33. Veal EA, Day AM, Morgan BA (2007) Hydrogen peroxide sensing and signalling.MolCell26:1-14

34. Youdim MBH, and Tenne M (1987) Methods Enzymol.142:617-626. 